\title{
Management of pancreatic ductal adenocarcinoma (PDAC): Progress in the past decade and challenges for the future
}

\author{
Roger Clementine ${ }^{1}$, Mas Leo1, Granier Sandra ${ }^{1}$, Colle Elise ${ }^{1}$, Neuzillet Cindy ${ }^{2}$ and Hammel Pascal ${ }^{1 *}$ \\ ${ }^{1}$ Department of Digestive Oncology, University Paris VII-Denis Diderot, Beaujon hospital (AP-HP), Clichy, France \\ ${ }^{2}$ Department of Digestive Oncology CLCC René Huguenin, Institut Curie, 35 rue Dailly, 92210 Saint-Cloud, France
}

\section{Epidemiology}

Pancreatic ductal adenocarcinoma (PDAC) is the fourth leading cause of cancer death in the United States with 41,615 deaths in 2015 as well as in Europe where 128,000 persons are expected to die from this tumor in $2018[1,2]$. Although the worldwide incidence is low with 4.2 per 100000 , and there are important geographic differences (from 7.4 per 100000 in North America to fewer than 1.5 in Central Africa), the incidence is rising in developed countries such as France, where it nearly doubled between 1982 and 2012 and ranges from 10.2 per 100 000 in men to 6.9 per 100000 in women [3]. Because the mortality rate will either remain unchanged or moderately increase in upcoming years, PDAC is expected to become the third leading cause of cancer death in the EU by 2025 and the second leading cause of cancer-related death in the United States by $2030[4,5]$.

\section{Risk factors}

PDAC is more frequent in the elderly and in men (sex ratio=1.5), and the incidence seems to differ depending on the ethnic group. Indeed, the reported incidence rates in the United States suggest a higher risk in the Afro-American population.

Environment and lifestyle: Established risk factors include smoking (with a 2-fold increased risk, accounting for an estimated $20 \%$ cases in the developed countries) and diet, with an increased risk associated with high calorie intake, red and processed meat, as well as soft drink consumption. Alcohol consumption of $\geq 30 \mathrm{~g} /$ day is also associated with a $20 \%$ increased risk of PDAC. On the other hand, fruit and vegetable consumption, as well as physical activity has been shown to be potential protective factors [6].

Predisposing conditions: Medical conditions associated with PDAC include obesity and the metabolic syndrome, a history of diabetes and chronic pancreatitis. In contrast, atopic allergies have been reported to be a protective factor. Several associations have been described but must still be confirmed or are a subject of debate: a history of cholecystectomy, gastrectomy, Helicobacter pylori infection, or non-O blood type. HBV and HCV infections have also been reported to be risks factors [6].

Genetic: A family history of PDAC is associated with a higher risk that increases in relation to the number of relatives concerned and results in an up to 32 -fold higher risk in patients with three or more first degree relatives (FDRs) [7]. Although as many as 10\% of PDAC are thought to have an inherited component, only a limited number of putative susceptibility genes have been identified to date. Indeed, only $15 \%$ of those with a family history of PDAC have an identified germinal predisposing mutation.

The main genes and genetic syndromes known to be associated with an increased risk of PDAC are summarized in Table 1 [7-12].

Improvements in sequencing technologies have resulted in the recent discovery of numerous other germline variants associated with a susceptibility to PDAC and should provide further useful information in the future to improve risk estimations, for earlier diagnosis in patients at risk and for possible personalized treatment [9].

Moreover, germinal mutations may not only be detected in patients with a family history of PDAC but also in a significant proportion of sporadic cases. The frequency of known PDAC-associated mutations in unselected patients in several studies ranges from $3.6 \%$ to $20 \%$. For example, $\mathrm{Hu}$ et al. [10] recently reported a $5.2 \%$ rate of deleterious mutations in six predisposition genes (CDKN2A, TP53, MLH1, BRCA2, ATM, and BRCA1) in 2687 patients with no family history of pancreatic cancer. Systematic pathogenic germline variant (PGV) testing in unselected patients diagnosed for PDAC (with no family or personal history of cancer) identified a significant number of patients with potentially clinically significant mutations that would not have been identified if the current criteria for germline mutation testing had been applied. In two prospective cohorts of 298 and 615 unselected PDAC, only $48 \%$ and $59 \%$ of PGV carriers would have been identified $[13,14]$. In addition, some of them can be targeted and represent future potential therapeutic targets (i.e. PARP inhibitors).

Thus, because detection of these mutations could help identify treatments and provide opportunities for the prevention and screening of the relatives of these patients, more appropriate genetic testing criteria are also needed.

${ }^{\star}$ Correspondence to: $\mathrm{P}=\mathrm{Pascal}$ Hammel, Department of Digestive Oncology, Beaujon hospital, 100 boulevard Leclerc, 92110 Clichy, France, Tel: + 3314087 56 14; E-mail: pascal.hammel@aphp.fr

Key words: pancreatic adenocarcinoma epidemiology, precancerous, chemotherapy, surgery

Received: April 23, 2019; Accepted: May 21, 2019; Published: May 23, 2019 


\section{Screening}

In 2012 the international cancer of the pancreas screening consortium (CAPS) published several statements on the screening of individuals at high risk of familial pancreatic cancer [7]. A conosortium agreement was reached that the following candidates should be screened:

- first-degree relatives (FDRs) of patients with PC with at least two affected FDRs

- patients with Peutz-Jeghers syndrome; and

- patients with p16, BRCA2 and hereditary non-polyposis colorectal cancer (HNPCC) mutation carriers with $\geq 1$ affected FDR.

Screening techniques should include EUS or MR imaging and any surgery should be performed in a high-volume center. No consensus was reached on the age to start or stop screening or the optimal interval for follow-up imaging. A recent meta-analysis of 16 studies including 1551 individuals at high risk of familial pancreatic cancer, reported a pooled proportion of screening goal achievement (defined as the diagnosis of T1N0M0 PDAC, PanIN3 or high grade IPMN) of $1.4 \%$ [15]. Because of the high risk of morbidity/mortality of pancreatic surgery, these results show the need for improvement in screening programs. In this same study, the pooled proportion of unnecessary surgeries was $68.1 \%$.

\section{Pre-cancerous lesions}

In addition to environmental factors and genetic predispositions, pre-malignant pancreatic lesions include pancreatic intraepithelial neoplasia (PanINs), intraductal papillary and mucinous neoplasms
(IPMN) and mucinous cystic neoplasms (MCN). Improvement in imaging techniques has resulted in a significant increase in the detection of pancreatic cysts that are mostly found incidentally. Their estimated prevalence is $2 \%-20 \%$ depending on the patient's age and the type of imaging, with a reported prevalence of clinically important lesions of $1 \%$ in current guidelines [16].

IPMN is the main preneoplastic pancreatic cystic lesion. These macroscopic lesions are divided into main duct (MD) IPMN and branch duct (BD) IPMN with a reported incidence of malignancies of $70 \%$ and $25 \%$, respectively $[17,18]$. Although early and systematic resection was practiced in the 1990's, ever since the Sendai guidelines in 2006 and the Fukuoka guidelines in 2012, a more conservative approach has been taken, especially for BD IPMN, based on criteria estimating the risk of malignancy. Nevertheless, the limits of these criteria were evaluated in several studies, resulting in a recent update of Fukuoka guidelines in 2017 (Table 2) [17,19].

These criteria recommend further evaluation (based on endoscopic ultrasound) and surveillance or surgery in patients diagnosed with IPMN. Surgical resection is strongly recommended in any patient in good condition with a high risk of stigmata. Patients should be treated in experienced centers with a highvolume of pancreatic surgery to limit the morbidity and mortality of prophylactic resections.

Large cohorts of patients with pancreatic cysts are being followed to improve knowledge of the natural history and risks of progression in these pre-cancerous lesions.

Table 1. Main genetic diseases predisposing to the development of PDAC

\begin{tabular}{|c|c|c|c|c|c|}
\hline Genetic syndrome & Oncogenic process & Mutation & $\begin{array}{c}\text { Percentage among familial } \\
\text { PDAC }\end{array}$ & Relative risk & $\begin{array}{c}\text { Cumulative risk of PDAC } \\
\text { by age } 70 \%\end{array}$ \\
\hline No family history & - & - & - & 1 & $0.5-1$ \\
\hline $\begin{array}{l}2 \text { first-degree relatives with } \\
\text { confirmed PDAC }\end{array}$ & \multirow{2}{*}{ Unknown } & Unknown & \multirow{2}{*}{$80-85$} & $4-6$ & $5-12$ \\
\hline $\begin{array}{l}\geq 3 \text { first-degree relatives with } \\
\text { confirmed PDAC }\end{array}$ & & Unknown & & $20-40$ & 40 \\
\hline \multirow{3}{*}{$\begin{array}{l}\text { Hereditary breast and ovarian } \\
\text { cancer (HBOC) }\end{array}$} & \multirow{4}{*}{ DNA Repair } & BRCA 2 & $5-20$ & $2-10$ & $4-5$ \\
\hline & & BRCA 1 & $1-5$ & $2-4$ & $3-4$ \\
\hline & & $\begin{array}{l}\text { PALB2, } \\
\text { FANC-C/G }\end{array}$ & $1-3$ & $2-6$ & $4-5$ \\
\hline Lynch syndrome & & $\begin{array}{l}\text { hMLH1, hMSH2, hMSH6, } \\
\text { PMS } 2\end{array}$ & $1-3$ & $4-8$ & $3-5$ \\
\hline Li Fraumeni syndrome & \multirow{4}{*}{$\begin{array}{l}\text { Cell growth and cell cycle } \\
\text { control }\end{array}$} & TP53 & $<2$ & $?$ & $?$ \\
\hline $\begin{array}{l}\text { Familial atypical multiple } \\
\text { mole melanoma (FAMMM) } \\
\text { syndrome }\end{array}$ & & P16/CDKN2A & $2-3$ & $10-25$ & $5-25$ \\
\hline Peutz-Jeghers syndrome & & LKB1/STK11 & $1-3$ & $100-130$ & $30-40$ \\
\hline Ataxia Telangiectasia & & ATM & $<2$ & $?$ & $?$ \\
\hline Hereditary pancreatitis & Cell injury & PRSS1 & $1-4$ & $50-80$ & $40-55$ \\
\hline
\end{tabular}

Table 2. Consensual clinical and imaging features that should lead to prompt management, according to Fukuoka guidelines [19]

\begin{tabular}{|l|l|}
\hline Worrisome features & 'High risk stigmata' \\
\hline - cyst size $\geq 3 \mathrm{~cm}$ & - obstructive jaundice \\
- thickened/enhancing cyst walls & - enhanced mural nodule $\geq 5 \mathrm{~mm}$ \\
- main pancreatic duct size between $5-9 \mathrm{~mm}$ & - main pancreatic duct $\geq 10 \mathrm{~mm}$ \\
- enhancing mural nodule $<5 \mathrm{~mm}$ & \\
- abrupt change in caliber of pancreatic duct with distal pancreatic atrophy & \\
- lymphadenopathy & \\
- elevated serum level of CA $19-9$ & \\
- rapid rate of cyst growth $>5 \mathrm{~mm} / 2$ years & \\
\hline
\end{tabular}




\section{Diagnosis}

Although ultrasound can be used in case of jaundice or abdominal pain as the first imaging technique, a reliable diagnosis cannot be obtained with this method and small pancreatic tumors cannot be excluded [20]. If the diagnosis is suspected clinically or by US, CT and MR imaging are the reference techniques and the characteristics of PDAC are now well known [21]. Although a recent study showed a significant incremental benefit in the diagnosis of pancreatic cancer and a positive influence in the staging and management of patients ${ }^{18} \mathrm{FDG}$ PET/CT is not recommended [22].

Endoscopic ultrasound can be useful in four situations:

- strong suspicion of PDAC that cannot be visualized on CT or MR imaging

- undetermined pancreatic mass (e.g. differential diagnosis with chronic pancreatitis or pseudo-tumoral auto-immune pancreatitis)

- need for pathological evidence if the diagnosis is doubtful when neoadjuvant treatment is planned in resectable tumors or before proposing chemotherapy in non-resectable tumors when there are no other more easily accessible tumoral lesions.

- an indication for endoscopic retrograde cholangiopancreatography (ERCP) for biliary drainage.

\section{Staging}

Once the diagnosis has been made, a chest-abdominal-pelvic CT scan is performed to assess the stage of the cancer. This test should be performed no more than four weeks before any planned surgery for pancreatic cancer to avoid unexpected metastases during the intervention [23]. CT should include three sequences: without contrast administration and after contrast administration during the arterial and portal phases. Tumor resectability depends on the size, the extension and especially vascular involvement of the tumor as well as the presence/absence of distant metastases (Table 3).

There are four tumor subtypes :

- resectable

- borderline resectable

- locally advanced

- metastatic.

Although abdominal magnetic resonance imaging (MR imaging) with cholangio-pancreatographic sequences are as specific and sensitive as $\mathrm{CT}$, this technique is limited by cost and availability and a thoracic CT must still be performed. Liver MR imaging with diffusion sequences is sometimes recommended before surgery of localized tumors to exclude small hepatic metastases that cannot be visualized on CT [8].

\section{Prognostic and diagnostic markers}

The poor prognosis of PDAC is mainly due to the difficulty of obtaining an early diagnosis and the limited efficacy of available therapeutics. Although there is a large window for surgical resection before progression from preneoplastic lesions to invasive cancer, the rate of advanced PDAC (stage III or IV) at diagnosis is more than $80 \%$. Because of the lack of reliable markers, no screening programs for PDAC are possible except in those with family risks. CA 19-9 is still the only biomarker used for the diagnosis and management of PDAC.

\section{CA 19-9:}

As a diagnostic marker: CA 19-9 has several limitations. It is a sialylated Lewis blood group antigen and can therefore not be used in Lewis a-b- patients who represent approximately $5-10 \%$ of this population [24]. Furthermore, the accuracy is reduced by a lack of specificity, and this marker may be elevated in extra-pancreatic malignancies and benign conditions such as cholestasis or diabetes. Thus, CA 19-9 has been shown to be ineffective for screening in asymptomatic populations because of the low positive predictive value. For example, only 4 cases of PDAC were identified in a Korean study including 70,940 asymptomatic patients and in a recent metaanalysis the sensitivity and specificity of CA $19-9$ was $78.2 \%$ and $82.8 \%$, respectively $[25,26]$.

As a prognostic marker: The prognostic value of CA 19-9 is probably better for therapeutic follow up.

Measurement of this marker at diagnosis has a good prognostic value. Survival in patients with normal serum levels $(<37 \mathrm{U} / \mathrm{ml})$ is better than in those with abnormal levels (32-36 months vs $12-15$ months). It is also useful when tumor resection is planned. Serum levels $\leq 100-200$ $\mathrm{U} / \mathrm{ml}$ are suitable for surgery, while higher levels suggest the presence of (micro)metastatic disease. A postoperative decrease $>20 \%-25 \%$ or normalization in CA 19-9 serum levels is associated with prolonged survival, as is a decrease after chemotherapy [27,28].

New biomarkers: Because of the limitations of CA 19-9, novel biomarkers are needed. Many approaches are under development to obtain earlier detection, improved predictive value and for follow-up. Some recent advances are described below.

Multi marker panel: To increase both sensitivity and specificity, multimarker panels have been proposed combining different serum proteins (with or without CA 19-9) for improved diagnostic performances [29]. Interesting results have been obtained with combinations including CA 19.9 and REG1+SYCN, thrombospondin A2, or more recently periostin (POSTN) + CA 242 [30-32]. These panels must be validated in large independent validation cohorts before they can be applied in routine practice.

Inflammatory and growth factors: Various inflammatory factors including chemokines, cytokines and growth factors are differentially

Table 3. Imaging features defining borderline and locally advanced PDAC

\begin{tabular}{|c|c|c|}
\hline \multicolumn{3}{|l|}{ NCCN 2015} \\
\hline Vessel & Borderline & Locally advanced \\
\hline Superior mesenteric vein/ Portal vein & $\begin{array}{l}\text { Contact } \geq 180^{\circ} \\
\text { Contact }<180^{\circ} \text { with caliber irregularity of the vein without occlusion and/ } \\
\text { or tumoral occlusion with possible surgical reconstruction }\end{array}$ & $\begin{array}{l}\text { Tumoral occlusion with no possible reconstruction, or invasion of } \\
\text { jejunal principal veins }\end{array}$ \\
\hline Superior mesenteric artery & Contact $<180^{\circ}$ & Contact $\geq 180^{\circ}$ \\
\hline Common hepatic artery & $\begin{array}{l}\text { Short contact, whatever the circumference, without invasion of the coeliac } \\
\text { trunk nor of the origin of the CHA, with possible surgical reconstruction }\end{array}$ & No possible surgical reconstruction \\
\hline Coeliac trunk & Contact $<180^{\circ}$ & Contact $\geq 180^{\circ}$ \\
\hline
\end{tabular}


expressed in patients with cancer, including PDAC. Thus, several panels have been developed combining certain analytes. Recently Mellby et al. [33] proposed a proteomic multiparametric analysis including 29 biomarkers (mainly targeting the tumor secretome or immunoregulatory proteins to reflect the systemic response) to discriminate early stage PDAC (I or II) from healthy controls with an AUC/sensitivity/specificity of $0.96 / 95 \% / 94 \%$ and $0.963 / 95 \% / 93 \%$ in two independent cohorts, respectively.

Metabolomics: Several changes occur in metabolic enzymes and there is an accumulation of key intermediates in PDAC as a result of reprogramming by the cancer cell metabolism in response to abnormal metabolic demands. Thus Johannes et al. [34] recently proposed a panel including five metabolites to discriminate early stage PDAC from healthy controls, reporting an AUC of 0.892 and improved results when it was combined with a previously validated biomarker panel (CA 19.9, LRG1, TIMP1) (AUC of 0.924) [35].

Besides serum protein markers, inflammatory, growth factors and metabolomic analysis, there is growing interest in a new field called liquid biopsy.

"Liquid biopsy": The recent discoveries in molecular pathology and the genetic alterations involved in the development and progression of cancer have led to the development of liquid biopsy, which is a promising tool because of the difficulty in biopsing PDAC.

This minimally invasive approach should make it possible to detect and analyze genetic material released from the tumor into the peripheral circulation including circulating tumor cells (CTCs), tumor nucleic acids (ctNAs), tumor RNAs (ctRNAs) and tumor-derived exosomes [36]. This technique is promising for early diagnosis, prognosis and PDAC disease monitoring. It may also provide valuable genomic and molecular information to help determine a non-invasive approach to the mutational landscape or methylation profiles of tumors.

Circulating tumor cells (CTCs): PDAC tumor-derived cells found in the peripheral circulation are highly heterogenous compared to other cancer types, making detection challenging (37). Several techniques have been developed for the detection of CTCs based on physical features, different cell surface proteins, markers or oncogene expression, with varying results. The only detection strategy approved

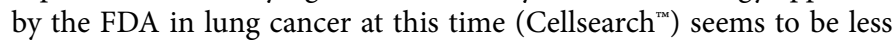
effective in PDAC. The clinical application of these techniques has been evaluated in several studies, with high variations in sensitivity [37]. Some have reported a correlation with tumor differentiation and overall survival in locally advanced PDAC, as well as a potential prognostic value in resectable and metastatic patients. Unified detection methods and validation in large cohorts are needed to assess the potential use in practice $[38,39]$.

ctDNA: Detection of ctDNA is based on the targeting of tumor specific PDAC mutations (mainly KRAS) in circulating free DNA (cfDNA). This approach has not yet been validated and the sensitivity and specificity must be clarified [37]. Because of the high frequency of KRAS mutations in this tumor, ctDNA detection would theoretically be useful for early detection. Nevertheless, the sensitivity in the study by Bettegowda et al. [38] was disappointing in an evaluation of 155 PDAC, with detectable ctDNA in only $48 \%$ of nonmetastatic patients. Several studies have also suggested that the sensitivity of KRAS mutation detection in plasma was low. Moreover, specificity may also be limited because detection rates of over $10 \%$ have been reported in patients with chronic pancreatitis [40]. ctDNA detection may be of interest as a prognostic marker in resectable patients and for the early assessment of treatment response in patients with nonresectable tumors. KRAS mutation detection may also be corrrelated to prognosis and TNM stage in both advanced and resected pancreatic cancers [41,42]. As for CTCs, the clinical application of CTCs is limited by small evaluation cohorts, low sensitivity and the lack of technical standardization.

Methylation profile: In addition to genomic abnormalities, epigenetic alterations in the methylation profile of ctDNA could also be of future interest. Several targets for abnormal DNA methylation associated with PDAC have been identified and combined to improve performance and may become new diagnostic markers in the future [43].

Circulating RNA: Circulating noncoding RNAs (ncRNA), especially miRNA and long non-coding RNA (lncRNA), are other future potential markers [44]. Several studies have identified and tested different circulating miRNA (the most extensively studied is miR-21) and reported their potential value in miRNA panels in both blood and tumor-derived exosomes [45]. miR-107 is especially promising as it may be useful as both a diagnostic marker and therapeutic target of PDAC [46].

Tumor-derived exosomes: Exosomes are small extracellular vesicles in the peripheral circulation whose components, proteins and nucleic acids from cancer cells may be useful as diagnostic and prognostic biomarkers. Glypican 1, a cell surface proteoglycan is specifically enriched on the surface of cancer-derived exosomes and has been reported by Melo et al. [47] to be a "near perfect" tool for discriminating PDAC patients from healthy controls and benign pancreatic diseases, with an AUC of 1.0.

Immunosorbent: Immunology has recently revolutionized many cancer treatment options and it could also provide other applications for prognostic markers in the future. The immunosorbent assay (an immune score quantification of tumors based on total tumor-infiltrating T-cell counts and cytotoxic tumor-infiltrating T-cell counts), which has already been validated in colorectal cancer, was evaluated in a Finnish study including 108 patients with PDAC undergoing surgical resection [48]. Results showed a significant correlation to survival, independent from TNM stage [49]. Further studies are needed in PDAC to determine whether the results in colon cancer could be applicable to obtain reliable new markers, as a guide to adjuvant treatment after surgery, for example.

\section{Treatment}

\section{Resectable tumors}

Only $10 \%$ to $20 \%$ of patients are eligible for curative surgery. Multidisciplinary decisions should be based on a recent imaging assessment, i.e. a CT scan less than three to four weeks old. To achieve R0 resection, surgery should be performed in a high-volume center to minimize both morbidity and mortality [50]. The increasing incidence of PDAC makes it urgent to improve surgeon training and develop both intermediate and high-volume centers.

The role of neo-adjuvant treatment (chemotherapy alone or with radiation therapy) must still be defined.

The goal is to:

- induce a tumoral response and favor R0 resection

- provide an observation period to identify aggressive tumors with early metastatic progression 
- treat potential micro-metastatic disease early

- test both tumor chemosensitivity and patient tolerance

Two main trials are in progress:

- NEOPAC: phase 3 trial investigating the efficacy of neo-adjuvant gemcitabine/oxaliplatin (or FOLFIRINOX after an amendment) chemotherapy plus adjuvant gemcitabine versus adjuvant gemcitabine only in patients with resectable tumors. The results are pending (NCT01314027) [47].

- PRODIGE48(PANACHE-01): open, non-comparative, randomized, multicenter phase II study designed to assess the safety and efficacy of two types of neo-adjuvant chemotherapy (FOLFIRINOX or FOLFOX) followed by surgery vs. direct surgery (NCT02959879).

The duration of adjuvant chemotherapy in patients who receive neoadjuvant treatment must also be defined defined and the role of radiation therapy must be prospectively assessed.

Up to $80 \%$ of patients who undergo surgery for localized PDAC will develop local or metastatic relapse [52]. Thus, adjuvant treatment has been systematically proposed since 2000 and should ideally begin within three months after surgery [53]. Since 2010, adjuvant gemcitabine has been the standard-of-care based on the ESPAC-3 trial which showed similar survival but less toxicity than with adjuvant 5-fluorouracil/folinic acid [54]. In 2017, the ESPAC-4 trial showed that gemcitabine plus capecitabine was superior to gemcitabine (28 vs 25.5 months, HR: 0.82, p:0.032) [55]. The results of the PRODIGE 24 trial were recently presented at the 2018 ASCO annual meeting. Compared to gemcitabine, modified FOLFIRINOX (mFOLFIRINOX) improved both disease-free (median: 21.6 vs 12.8 months, HR:0.58, p<0.001) and overall (median: 54.4 vs 35 , HR:0.64, $\mathrm{p}=0.003$ ) survival, respectively. Thus, FOLFIRINOX should be considered the new standard of care for ECOG 0-1 European and American patients [56]. The Japanese JASPAC 01 trial also showed that $S 1$ was superior to gemcitabine and $\mathrm{S} 1$ is therefore the reference adjuvant treatment in Japan [57]. Addition of targeted therapy (erlotinib or sorafenib) to gemcitabine failed to improve overall and disease-free survival [58,59]. Finally, the results of the phase III APACT trial (gemcitabine plus nab-paclitaxel versus gemcitabine) are pending. Figure 1 summarizes the progression of median overall survival in resected PDAC.

There is no clear consensus on the role of adjuvant radiotherapy (some studies have even suggested a deleterious effect on survival), and it is therefore not recommended [60-62].

\section{Borderline and locally advanced tumors}

Borderline tumors: A tumor is classified as borderline in the presence of limited vascular contact and the risk of R1 resection is not negligible with first line surgical treatment in these cases. Thus, induction treatment may be considered the best option. Some recent studies reported that induction therapy with FOLFIRINOX was effective for the R0 resection rate, pathological response and overall survival $[63,64]$. The PRODIGE 44 (PANDAS) trial is an ongoing randomized phase II study assessing the efficacy of induction chemotherapy by modified FOLFIRINOX followed or not by chemoradiotherapy. Indeed, the use of radiation therapy combined with capecitabine as a radiosensitizer seems to increase the pathological response [64].

There are no existing data on adjuvant treatment in operated patients who have received induction chemotherapy. Follow-up CT scan after induction treatment is difficult, especially to predict R0 resection. Resection may be R0 or even N0 even with an unchanged imaging status by the NCCN classification [65]. It has been shown that a major pathological response can be predictive of survival [63].

Overall, a large prospective randomized trial is needed to clearly evaluate the role of induction therapy in these patients.

Locally advanced tumors (LAPC): Although this may seem surprising, gemcitabine is still the reference treatment 21 years after it became available [66]. There was no significant difference in overall survival with the addition of erlotinib to gemcitabine compared to gemcitabine alone [67]. Results obtained with FOLFIRINOX are promising, and the results of the NEOPAN study, a prospective

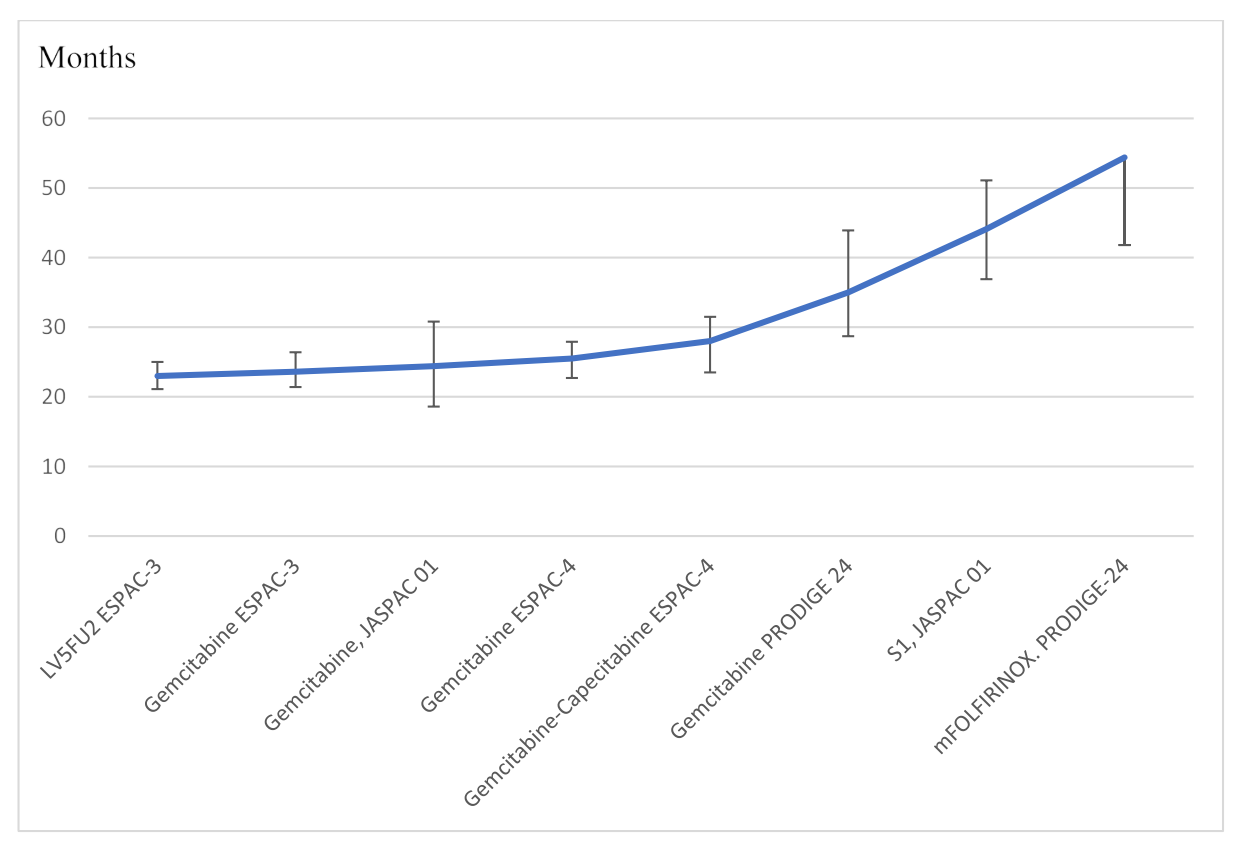

Figure 1. Evolution of median overall survival from 2001 to 2018 according to adjuvant treatment in resected PDA 
randomized phase III trial comparing this combination to gemcitabine are awaited $[68,69]$.

The preliminary results of the LAPACT phase II study assessing the efficacy and safety of nab paclitaxel plus gemcitabine were reported at the 2018 ASCO meeting and showed promising antitumor activity with an overall response and disease control rates of $33 \%$ and $78 \%$ respectively with good tolerance and quality of life. In addition, induction chemotherapy allowed tumor resection in 16/107 patients (15\%), almost half with R0 resection [70].

There is no consensus on the role of radiotherapy in LAPC [71]. While some studies have reported a benefit in overall survival with chemoradiotherapy compared to chemotherapy alone, the LAP07 trial found no significant difference $[67,72,73]$. Capecitabine seems to be superior and less toxic than gemcitabine as a radiosensitizer [74]. It is now generally accepted that a period of induction chemotherapy is needed prior to radiation therapy to detect patients with rapid metastatic progression. One important goal is to propose a therapeutic break until progression in patients who can stop chemotherapy after radiation [65]. In the presence of a major tumoral response without the development of metastases, surgery can be proposed to certain highly selected patients.

\section{Metastatic cancer}

First line: Since it was introduced in 1997, gemcitabine has been the reference treatment in metastatic tumors [64]. For nearly 15 years, almost all combinations of gemcitabine with other drugs have failed to improve results. Indeed, several meta-analyses have showed that the toxicity of doublet chemotherapy offsets the marginal benefit to overall survival and may even be harmful in patients with poor performance status [75,76].

The combination of gemcitabine to targeted therapy has failed in numerous studies except for the combination of gemcitabine and erlotinib which was found to have a statistically significant but clinically irrelevant gain in overall survival $(<1$ month) [77-79]. The lack of efficacy of erlotinib in the LAP07 trial in LAPC confirmed the limited role of this drug in pancreatic cancer [67]. The major advancement came in 2010 from the phase III PRODIGE-4/ACCORD-11 trial. The FOLFIRINOX combination was found to be highly superior to gemcitabine (OS 11.1 vs 6.8 months, $\mathrm{HR}=0.57, \mathrm{p}<0.001$ ). This protocol was limited to patients younger than 75 years of age in good condition (PS 0-1) and without cholestasis (bilirubin $<1.5$ fold the upper normal value) [80]. More adverse events occurred in the FOLFIRINOX group, especially febrile neutropenia (5.4\%).

A retrospective study then suggested that a lightened, modified FOLFIRINOX (suppression of 5-FU bolus) had an improved safety profile with similar efficacy [81]. The results of the PANOPTIMOX study recently presented at the 2018 ASCO annual meeting showed that maintenance with LV5FU2 is feasible and as effective as the continuation of FOLFIRINOX in patients with metastatic PDAC controlled after 4 months of induction chemotherapy with FOLFIRINOX [82]. These strategic trials are important to optimize the quality of life of patients by limiting (neuro)toxicity as much as possible.

In 2013, the combination of nab-paclitaxel and gemcitabine was also shown to be superior to gemcitabine alone for overall survival (8.5 vs 6.7 months, $\mathrm{HR}=0.72, \mathrm{p}<0.001$ ) in the phase III MPACT trial [82]. Patients with a Karnofsky performance-status score of 70 or more were eligible.
A comparison of FOLFIRINOX and gemcitabine-nab-paclitaxel has not been performed to date. Some studies have suggested that the FOLFIRINOX combination is superior $[83,84]$.

Finally, gemcitabine alone should be proposed in patients with PS 2and in patients with PS 3-4, the best support care is recommended [8].

Second line: About $50 \%$ of patients are eligible for a second line of treatment following tumor progression with first line therapies. Fluorouracil plus nanoliposomal irinotecan (or fluorouracil plus irinotecan) is the preferred second-line therapy in patients with PS 0-1 who have received first-line treatment with gemcitabine plus nab-paclitaxel. This combination has been shown to be superior to flurorouracil plus folinic acid in the phase III NAPOLI trial (OS 6.1 vs 4.2 months, $\mathrm{HR}=0.67, \mathrm{p}=0.012$ ) [85].

Patients with PS 0-1 who have received FOLFIRINOX as a firstline treatment can receive gemcitabine alone or associated with nabpaclitaxel as second-line therapy [8]. The results of L-asparaginase combined with cytotoxic chemotherapy (depending on the first line treatment) were promising in the randomized phase II GRASPANC-01 trial and are now being tested in a phase III trial (TRYBECA) [86].

Currently, despite controversial data, fluorouracil plus oxaliplatin can be considered the second-line therapy option in patients who remain in good condition after undergoing first-line treatment with gemcitabine-based chemotherapy. A randomized phase 3 trial (CONKO-003) showed the efficacy of OFF (oxaliplatin, fluorouracil, folinic acid) on overall survival ( 5.9 vs 3.3 months, $\mathrm{p}=0.01$ ) compared to FF (without oxaliplatin) [87]. However, this benefit was not confirmed in the PANCREOX phase III randomized trial comparing mFOLFOX6 to FU-Leucovorin [88]. Patients with a PS of 2 may receive secondline therapy with gemcitabine or fluorouracil after evaluation in a multidisciplinary meeting.

There is currently no available robust data about third-line therapy.

\section{Therapeutic research pathways}

Although the new cytotoxic chemotherapy regimens discussed above have recently become available with improved outcomes, new therapeutic options are urgently needed. As mentioned, the benefit of targeted therapies remains very limited $[84,85]$.

Thus, researchers have been investigating new concepts and pathways, based on growing knowledge of the molecular mechanisms involved in PDAC carcinogenesis and its microenvironment properties. This has led to the development of new approaches to obtain effective antitumoral effects [89].

Molecular pathology: Improvements in molecular biology have resulted in the development of molecular classifications of PDAC to identify subgroups of patients and potential clinical applications. Since 2011, several classifications have been published using different techniques to characterize the tumor and its microenvironment, revealing a significant heterogeneity among PDAC [90-92].

Waddell et al. [93] performed deep whole-genome sequencing of 100 PDAC and confirmed the well-known mutated genes in PDAC (KRAS, TP53, CDKN2A, SMAD4). They classified these tumors into four subtypes based on their structural variation profile, as stable (20\%), locally rearranged (30\%), scattered (36\%) and unstable (14\%). The unstable subtype was characterized by a high genomic instability suggesting defects in DNA maintenance systems, and a high correlation between this subtype and a BRCA mutational signature (previously described associated with deleterious mutations in BRCA1 or BRCA2 in 
breast, ovarian and pancreatic cancer) was observed. Further analysis of the outcome in these patients revealed a high sensitivity to platinumbased chemotherapy regimens, paving the way to predicting platinum responsiveness in a subpopulation of patients.

In the next step more consensual, unified molecular classifications should be established and several technical challenges in deep wholegenome sequencing must be solved before this approach can be used in clinical practice.

Microenvironment: PDAC displays a marked desmoplastic stromal reaction, that is often greater than the epithelial component of the tumor itself. This complex structure is composed of extracellular matrix (ECM) components and various cell types in which cancer associated fibroblasts (CAFs) and especially pancreatic stellate cells (PSC) appear to play a major role. They are responsible for ECM overproduction and secreting various factors resulting in a fibrotic and hypoxic microenvironment. Thus, these elements have been identified as important pro-tumoral partners of cancer cells in PDAC, promoting tumor growth, invasion, metastasis and resistance to chemotherapy [94]. Stromal abundance and activity are correlated to survival, suggesting that desmoplasia may play a prognostic role in PDAC and providing a potential new target for therapeutic strategies [95]. Several WHAT? are being developed to interfere with signaling pathways involved in this desmoplastic reaction by targeting the TGF $\beta$ pathway or Focaladhesion Kinases. Retinoic acid and vitamin D, which have both been shown to induce PSC quiescence in pre-clinical models, are also under evaluation. Another promising approach directly targets one of the ECM components, hyaluronic acid (HA). PEGPH20 is a PEGylated human recombinant hyaluronidase enzyme leading to the degradation of stromal HA and a decrease in interstitial pressure, thus promoting intra-tumoral perfusion and exposure to chemotherapy [96]. The 109202-HALO randomized phase II study evaluated the combination of PEGPH20 with gemcitabine plus nab-paclitaxel chemotherapy as firstline treatment in patients with metastatic PDAC. Overall progressionfree survival was significantly improved with combination therapy (HR: $0.73, p=0.049$ ), but especially in patients with HA-high tumors (HR: $0.51 ; p=0.048$ ) [97]. A phase III study of PEGPH20 including HA high patients alone is ongoing (NCT02715804). Surprisingly, the addition of PEGPH20 to mFOLFIRINOX appeared to be detrimental $(\mathrm{HR}=0.48)$ in a study of SWOG (NCT 019599139) by Ramathan et al. [98] probably because of the toxicity of the backbone chemotherapy.

BRCA mutation carriers: BRCA mutation carriers are the exception in PDAC and the only subset of patients in whom personalized treatment is close [11]. PDAC associated with the germline BRCA2 mutation is found in $4 \%-17 \%$ of families with a family history of PDAC history and occurs in $10 \%$ of BRCA 2 families with an increased risk of 3 to 6 -fold compared to non-carriers. The prevalence of the germline BRCA2 mutation in apparently sporadic PDAC is $4 \%-7 \%$, and 10 $20 \%$ in the Jewish Ashkenazi population. The BRCA 1 and 2 genes are key regulators of the homologous recombination (HR), a highfidelity repair system of double-strand DNA breaks and DNA crosslinking damages induced by DNA-damaging agents [11]. BRCA 2 loss of function induces multiple spontaneous chromosomal aberrations and genetic instability. Thus, therapeutics that exploit the inability of BRCA2-mutated tumors to repair DNA may be beneficial in these subsets of patients. Two main applications have been reported and evaluated thus far.

Platinum salts and radiation therapy: DNA-targeting cytotoxic agent platinum salts induce double-strand breaks that are not fixed in BRCA2 mutated tumors, which lack HR repair resulting in the accumulation of DNA damage leading to cell death. Thus, as suggested by Waddell et al. [93] prolonged survival could be expected with platinum-based treatments in this population. Numerous studies have reported prolonged survival in ovarian and breast cancers in BRCA mutation carriers who receive platinum salts and several retrospective case series have found a similar effect in BRCA2 mutation carriers with advanced PDAC $[99,100]$. Nevertheless, BRCA2 mutated tumors become resistant to platinum salts over time.

PARP inhibitors: olaparib, rucaparib, veliparib, ABT-888: An alternative to the HR system used in BRCA mutated tumors is another, lower fidelity DNA repair mechanism: the base excision repair complex that relies on an enzyme, the poly-ADP-ribose polymérase PARP. Thus, PARP inhibitors (PARPi) have been developed to deprive BRCA mutated (BRCAm) cells from this alternative repair mechanism to favor cell death due to the accumulation of DNA damage. The results of several studies evaluating PARPi monotherapy in BRCA2 mutation carriers have been promising. Two phase II studies including 23 and 19 patients with BRCAm, pretreated, advanced PDAC reported interesting response rates $(21.7 \%$ and $15.8 \%)$ and disease control rates after PARP inhibitor monotherapy (olaparib or rucaparib) [100,101]. Although a third study testing veliparib as a single agent in 16 BRCAm pretreated patients did not report any confirmed response, tumoral control was found $\geq 8$ weeks in $25 \%$ of patients [102].

PARPi are also expected to be beneficial in combination with cytotoxic chemotherapies. A phase 1 study evaluating PARPi in combination with gemcitabine showed a non-significant but interesting doubled overall response rate ( $27 \%$ vs $14 \%$ ) compared to gemcitabine alone. The BRCA status was only known in a few patients in this study (10/23) [103]. Another phase I study evaluated the association of veliparib with gemcitabine and cisplatin in two cohorts of untreated advanced PDAC, one with BRCA mutations $(n=9)$, the other without $(\mathrm{n}=7)$. The objective response rate in the BRCAm cohort was $77.8 \%(7 / 9)$ vs $0 \%$ in the BRCA wildtype (wt) arm. Overall survival in the BRCAm and BRCAwt arms was 23.3 months and 11 months, respectively [104]. Phase II and III studies evaluating PARPi as monotherapy or in association with chemotherapy in larger populations of PDAC are ongoing (NCT02677038, NCT01585805, NCT01489865). For example, the POLO study is evaluating the potential efficacy of olaparib as maintenance therapy in patients with sporadic PDAC and BRCA germline mutations (NCT02184195).

As suggested in several studies including the work by Connor et al. [105] PDAC associated with deficiencies in HR repair are not limited to germline BRCA gene mutations. Other genes pooled as "BRACness phenotype" related to DNA maintenance defects may be targeted by these therapies in future clinical trials [106].

Other research pathways: Some of the other approaches being investigated to develop new treatments include:

RAS pathway inhibition, as activating KRAS mutations are present in $>90 \%$ of PDAC and are known to play a key role in PDAC carcinogenesis.

- Targeting the abnormal cancer cell metabolism because the significant needs of cancer cells for energy and tumor microenvironment constraints result in adptative cellular mechanisms which are potential therapeutic targets.

\section{- Immune therapies.}

Some of the main results and ongoing trials in these fields are summarized in Table 4. 
Table 4. Main therapeutic research pathways for PDAC

\begin{tabular}{|c|c|c|c|}
\hline The RAS pathway & Tumoral metabolism & The stroma & Immune therapies \\
\hline $\begin{array}{l}\text { - MEK inhibitors (pimasertib) } \\
\text { Negative studies in association with } \\
\text { Gemcitabine [122]. } \\
\text { Modest benefit with the association MEKi + } \\
\text { mTORi in phase Ib study [123]. } \\
\text { - interfering RNAs: Encouraging pre- } \\
\quad \text { clinical studies [124], phase II ongoing in } \\
\text { association with chemotherapy in locally } \\
\text { advanced PDAC (NCT01676259) } \\
\text { Oncolytic viruses: Reolysin } \\
\text { Disappointing results in association with } \\
\text { chemotherapy [125,126]. } \\
\text { Encouraging results in association with CPI } \\
\text { in a phase IB trial (NCT02620423) } \\
\text { Pre-clinical: } \\
\text { CRISPR-Cas technology: anti tumoral } \\
\text { efficacy demonstrated in vitro and in } \\
\text { vivo [127] } \\
\text { Seven-In-Absentia Homolog (SIAH) } \\
\text { inhibition: } \\
\text { Tumorigenesis complete blockage of } \\
\text { pancreatic cancer cells in pre clinical models } \\
{[128] .}\end{array}$ & $\begin{array}{l}\text { - L-asparaginase: } \\
\text { PFS and OS benefit reported in the phase II } \\
\text { GRASPANC trial [86] } \\
\text { Phase III ongoing. } \\
\text { - Off label treatments [129]: } \\
\text { - Vitamin C } \\
\text { Phase I with encouraging results, phase II } \\
\text { beginning } \\
\text { Hydroxychloroquine } \\
\text { Several trials ongoing (NCT01978184; } \\
\text { NCT01128296; NCT01506973; } \\
\text { NCT01494155). Disappointing results in } \\
\text { human studies, one interim report from a } \\
\text { phase II study with encouraging results [130]. }\end{array}$ & $\begin{array}{l}\text { Pegvorhyaluronidase alfa (PEGPH20) } \\
\text { Positive phase II study [131]. } \\
\text { International phase III study (HALO 301) } \\
\text { ongoing (NCT02715804). } \\
\text { - The TGF B pathway } \\
\text { - TGFB ligand inhibitor: Trabedersen } \\
\quad \text { (AP12009) } \\
\text { Encouraging OS in phase I/II study [132]. } \\
\text { - TGFB receptor inhibitor: Galunisertib } \\
\quad \text { (LY2157299) } \\
\text { Interesting results in two phase II studies } \\
\text { (NCT01373164) [133]. } \\
\text { Phase IB study ongoing in association with } \\
\text { Durvalumab (NCT02734160). } \\
\\
\text { Focal-adhesion kinase } \\
\text { (FAK) inhibitors: } \\
\text { Phase I clinical trials beginning with FAK } \\
\text { inhibitor Defactinib (PF-04554878 or VS- } \\
\text { 6063) associated with CPI in pancreatic } \\
\text { cancer and other tumors (NCT02546531, } \\
\text { NCT02758587) } \\
\text { Retinoic acid: } \\
\text { Phase IB study ongoing evaluating } \\
\text { ATRA associated with Gem-Abraxane in } \\
\text { advanced or metastatic pancreatic cancer } \\
\text { (EudraCT2015-002662-23). } \\
\text { paricalcitol with immunotherapy } \\
\text { (NCT03331562). } \\
\text { chemotherapy are ongoing (NCT02030860), } \\
\text { as well as a phase II study combining } \\
\text { - Vitamin D: } \\
\text { - }\end{array}$ & 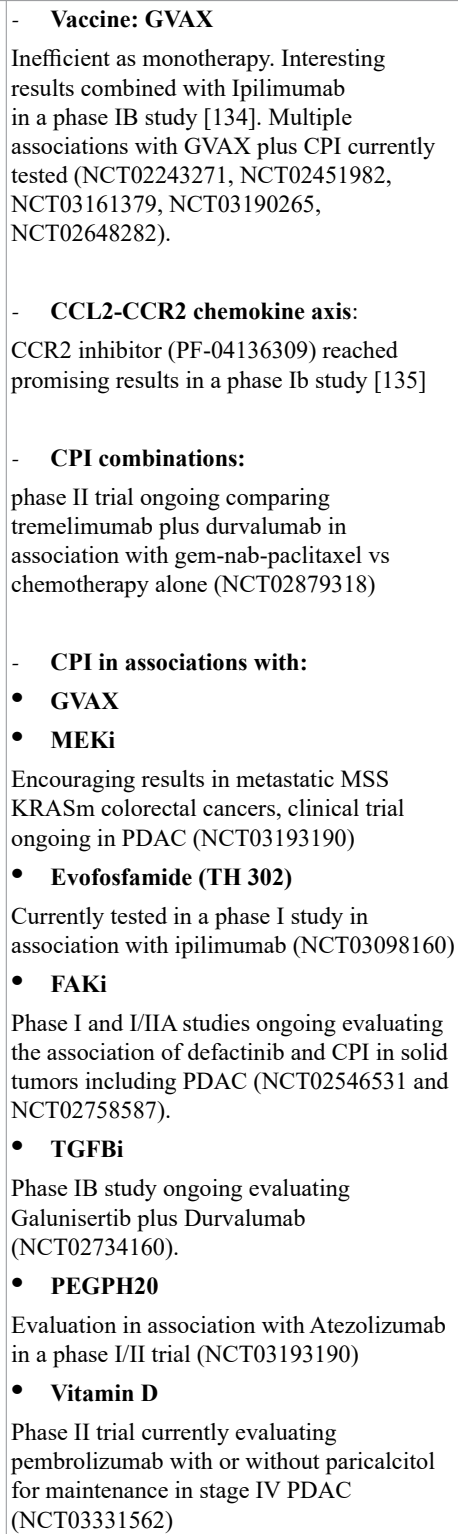 \\
\hline
\end{tabular}

\section{Supportive care}

Supportive care must play a central role in PDAC patients, whatever the tumor stage and should begin early, during the diagnostic process. Briefly, supportive care must consider and manage the following complications: pain, malnutrition, biliary and/or digestive obstructions, depression and anxiety and venous thromboembolism. Supportive care is absolutely necessary to optimize the general condition of patients so that they can receive potentially effective but aggressive treatments.

Pain management: Pain is a frequent symptom in patients with non resectable PDAC. It can be severe, thus preventing the appropriate administration of antitumoral treatments. Both the nociceptive and neuropathic components of pain should be carefully evaluated. Pharmaceutical analgesics are used according to the WHO three-step ladder and anti-epileptic drugs such as gabapentin and pregabalin should be included in case of neuropathic pain [107]. Pain can sometimes be refractory to opioids leading to dose escalation and potentially deleterious side effects. Besides opioid rotation, locoregional treatments such as coeliac plexus neurolysis guided by endoscopic ultrasound can be discussed, keeping in mind the possibility of rare but potentially severe pancreatic complications (acute pancreatitis, abcess) or even paraplegia. Coeliac plexus neurolysis is performed by injecting absolute alcohol into the coeliac plexus neural network of ganglia. A meta-analysis showed a significant reduction in pain at four weeks that was not maintained at eight weeks [108].

Venous thromboembolism: Primary thromboprophylaxis can be proposed in high risk patients as defined by the Khorana Score (Table 5) [109].

Malnutrition: Over $80 \%$ of PDAC patients report weight loss at diagnosis and over a third of these patients report a weight loss $>10 \%$ of their initial body weight [110]. 
Table 5. Prediction of the risk of thrombosis in patients with cancer

Patients characteristics

Very high-risk primary cancer type (stomach, pancreas) RISK SCORE

High-risk primary cancer type (lung, lymphoma, gynecologic, bladder, testicular)

Prechemotherapy platelet count $\geq 350000 / \mathrm{mm}^{3}$

Hemoglobin level $<10 \mathrm{~g} / \mathrm{dl}$ or use of red cell growth factors

Prechemotherapy leucocyte count $>11000 / \mathrm{mm}^{3}$

Body mass index $\geq 35 \mathrm{~kg} / \mathrm{m}^{2}$

High-risk score $\geq 3$; Intermediate-risk score $=1-2$; Low-risk score $=0$

A recent study revealed that nutritional support provided within three months after diagnosis could improve survival. More than $60 \%$ of patients had a high malnutrition risk at baseline, which was correlated with poorer PS [111]. Therefore, patients should be screened for malnutrition at diagnosis and nutritional support, if necessary, should be begun early on. Based on the ESPEN guidelines, nutritional intervention to increase oral intake is recommended in cancer patients who are able to eat but are at risk of being malnourished [112]. This includes dietary advice, treatment of symptoms and disturbances impairing food intake (nutrition impact symptoms) as well as oral nutritional supplements. Restrictive diets or fasting should be avoided in patients with PDAC as it can worsen weight loss and generate sarcopenia [113]. When oral nutrition remains inadequate despite nutritional interventions, enteral nutrition should be preferred to parenteral nutrition, unless there is a contra-indication (occlusion). When oral food intake has been decreased severely for a prolonged period of time, nutritional support should be increased slowly over several days with regular assessment of potassium, magnesium and phosphate level to prevent a refeeding syndrome.

Physical activity: Many patients ask if adapted physical activity (APA) is feasible and safe during cancer treatment while others do not even imagine being able to practice APA. It has been proven that exercise is not only safe but has a positive effect on health-related quality of life and fatigue both during and after treatment as well as on treatment tolerance and adherence in patients with cancer [114116]. Moreover, in breast-cancer and colon-cancer patients, physical activity is associated with reduced specific and non-specific mortality [117]. Indeed, preliminary evidence showed that exercise may favorably influence circulating levels of insulin, insulin-related pathways, inflammation and immunity [118-120].

The APA program should be individualized according to the patient's physical fitness, exercise preferences, psychological function and expectations, the tumor characteristics (stage, treatment, and tolerance) and the social environment. A combined aerobic exercise and resistance-training program should be favored. Patient adherence to the APA program is crucial for its efficacy. However, the effect of physical activity has not been examined specifically in patients with PDAC. Two prospective and randomized trials are in progress to assess its potential effect on both fatigue and quality of life in patients with unresectable (APACaP) or resected PDAC (APACaPOp) [121].

\section{Conclusion}

While significant progress has been made in the management of PDAC over the past decade, the rate of long-term survivors remains very low. Sustained efforts in all fields are still strongly needed to improve the prognosis of this devastating disease.

\section{References}

1. Siegel RL, Miller KD, Jemal A (2018) Cancer statistics. CA Cancer J Clin 68: 7-30. [Crossref]
2. Ferlay J, Colombet M, Soerjomataram I, Dyba T, Randi G, et al. (2018) Cancer incidence and mortality patterns in Europe: Estimates for 40 countries and 25 major cancers in 2018. Eur J Cancer 103: 356-387.

3. Drouillard A, Manfredi S, Lepage C, Bouvier AM (2018) Epidemiology of pancreatic cancer. Bull Cancer 105: 63-69. [Crossref]

4. Ferlay J, Partensky C, Bray F (2016) More deaths from pancreatic cancer than breast cancer in the EU by 2017. Acta Oncol 55: 1158-1160. [Crossref]

5. Rahib L, Smith BD, Aizenberg R, Rosenzweig AB, Fleshman JM, et al. (2014) Projecting cancer incidence and deaths to 2030: The unexpected burden of thyroid, liver, and pancreas cancers in the united states. Cancer Res 74: 2913-2921.

6. Maisonneuve P, Lowenfels AB (2015) Risk factors for pancreatic cancer: a summary review of meta-analytical studies. Int J Epidemiol 44: 186-198. [Crossref]

7. Canto MI, Harinck F, Hruban RH, Offerhaus GJ, Poley J-W, et al. (2013) International Cancer of the Pancreas Screening (CAPS) Consortium summit on the management of patients with increased risk for familial pancreatic cancer. Gut 62: 339-3347.

8. Neuzillet C, Gaujoux S, Williet N, Bachet J-B, Bauguion L, et al. (2018) Pancreatic cancer: French clinical practice guidelines for diagnosis, treatment and follow-up (SNFGE, FFCD, GERCOR, UNICANCER, SFCD, SFED, SFRO, ACHBT, AFC). Dig Liver Dis 50: 1257-1271.

9. Zhan W, Shelton CA, Greer PJ, Brand RE, Whitcomb DC (2018) Germline variants and risk for pancreatic cancer: A systematic review and emerging concepts. Pancreas 47: 924-936.

10. Hart SN, Polley EC, Gnanaolivu R, Shimelis H, Lee KY, et al. (2018) Association between inherited germline mutations in cancer predisposition genes and risk of pancreatic cancer. JAMA 319: 2401.

11. de Mestier L, Danset J-B, Neuzillet C, Rebours V, Cros J, et al. (2016) Pancreatic ductal adenocarcinoma in BRCA2 mutation carriers: Table 1. Endocr Relat Cancer 23: T57-67.

12. Rebours V, Lévy P, Ruszniewski P (2012) An overview of hereditary pancreatitis. Dig Liver Dis 44: 8-15. [Crossref]

13. Brand R, Borazanci E, Speare V, Dudley B, Karloski E, et al. (2018) Prospective study of germline genetic testing in incident cases of pancreatic adenocarcinoma: Genetic testing in pancreatic adenocarcinoma. Cancer 124: 3520-3527.

14. Lowery MA, Wong W, Jordan EJ, Lee JW, Kemel Y, et al. (2018) Prospective evaluation of germline alterations in patients with exocrine pancreatic neoplasms. J Natl Cancer Inst 110: 1067-1074.

15. Paiella S, Salvia R, De Pastena M, Pollini T, Casetti L, et al. (2018) Screening/ surveillance programs for pancreatic cancer in familial high-risk individuals: A systematic review and proportion meta-analysis of screening results. Pancreatology 18: $420-428$.

16. Mella JM, Gómez EJ, Omodeo M, Manzotti M, Roel M, et al. (2018) Prevalence of incidental clinically relevant pancreatic cysts at diagnosis based on current guidelines. Gastroenterol Hepatol 41: 293-301. [Crossref]

17. Tanaka M, Fernández-del Castillo C, Adsay V, Chari S, Falconi M, et al. (2012) International consensus guidelines 2012 for the management of IPMN and $\mathrm{MCN}$ of the pancreas. Pancreatology 12: 183-197.

18. Fong ZV, Ferrone CR, Lillemoe KD, Fernández-del Castillo C (2016) Intraducta papillary mucinous neoplasm of the pancreas: Current state of the art and ongoing controversies. Ann Surg 263: 908-917.

19. Tanaka M, Fernández-del Castillo C, Kamisawa T, Jang JY, Levy P, et al. (2017) Revisions of international consensus Fukuoka guidelines for the management of IPMN of the pancreas. Pancreatology 17: 738-753.

20. Lee ES, Lee JM (2014) Imaging diagnosis of pancreatic cancer: A state-of-the-art review. World J Gastroenterol 20: 7864-7877. [Crossref]

21. Al-Hawary MM, Francis IR, Chari ST, Fishman EK, Hough DM, et al. (2014) Pancreatic ductal adenocarcinoma radiology reporting template: Consensus statement of the society of abdominal radiology and the american pancreatic association. Gastroenterology 146: 291-304.e1

22. Ghaneh P, Hanson R, Titman A, Lancaster G, Plumpton C, et al. (2018) PET-PANC multicentre prospective diagnostic accuracy and health economic analysis study of the impact of combined modality 18 fluorine-2-fluoro-2-deoxy-d-glucose positron emission tomography with computed tomography scanning in the diagnosis and management of pancreatic cancer. Health Technol Assess Winch Engl 22: 1-114.

23. Raman SP, Reddy S, Weiss MJ, Manos LL, Cameron JL, et al. (2015) Impact of the time interval between MDCT imaging and surgery on the accuracy of identifying metastatic disease in patients with pancreatic cancer. Am J Roentgenol 204: W37-42. 
24. Kannagi R (2007) Carbohydrate antigen sialyl lewis a - Its pathophysiological significance and induction mechanism in cancer progression. Chang Gung Med J 30: 189-209.

25. Kim J-E, Lee KT, Lee JK, Paik SW, Rhee JC, et al. (2004) Clinical usefulness of carbohydrate antigen 19-9 as a screening test for pancreatic cancer in an asymptomatic population. J Gastroenterol Hepatol 19: 182-186.

26. Poruk KE, Gay DZ, Brown K, Mulvihill JD, Scaife CL, et al. (2015) The clinical utility of CA 19-9 in pancreatic adenocarcinoma: Diagnostic and prognostic updates. Curr Mol Med 13: 340-351. [Crossref]

27. Ballehaninna UK, Chamberlain RS (2012) The clinical utility of serum CA 19-9 in the diagnosis, prognosis and management of pancreatic adenocarcinoma: An evidencebased appraisal. J Gastrointest Oncol 3: 15.

28. Chiorean EG, Von Hoff DD, Reni M, Arena FP, Infante JR, et al. (2016) CA19-9 decrease at 8 weeks as a predictor of overall survival in a randomized phase III tria (MPACT) of weekly nab -paclitaxel plus gemcitabine versus gemcitabine alone in patients with metastatic pancreatic cancer. Ann Oncol 27: 654-660.

29. Chang JC, Kundranda M (2017) Novel diagnostic and predictive biomarkers in pancreatic adenocarcinoma. Int J Mol Sci 18: 667.

30. Makawita S, Dimitromanolakis A, Soosaipillai A, Soleas I, Chan A, et al. (2013) Validation of four candidate pancreatic cancer serological biomarkers that improve the performance of CA19.9. BMC Cancer 13: 404.

31. Kim J, Bamlet WR, Oberg AL, Chaffee KG, Donahue G, et al. (2017) Detection of early pancreatic ductal adenocarcinoma with thrombospondin-2 and CA19-9 blood markers. Sci Transl Med 9: eaah5583.

32. Dong D, Jia L, Zhang L, Ma N, Zhang A, et al. (2018) Periostin and CA242 as potential diagnostic serum biomarkers complementing CA19.9 in detecting pancreatic cancer. Cancer Sci 109: 2841-2851.

33. Mellby LD, Nyberg AP, Johansen JS, Wingren C, Nordestgaard BG, et al. (2018) Serum biomarker signature-based liquid biopsy for diagnosis of early-stage pancreatic cancer. J Clin Oncol 36: 2887-2894.

34. Fahrmann JF, Bantis LE, Capello M, Scelo G, Dennison JB, et al. (2018) A plasmaderived protein-metabolite multiplexed panel for early-stage pancreatic cancer. $J$ Nat Cancer Inst 111: 372-379.

35. Capello M, Bantis LE, Scelo G, Zhao Y, Li P, et al. (2017) Sequential validation of blood-based protein biomarker candidates for early-stage pancreatic cancer. $J$ Natl Cancer Inst 109: djw266. [Crossref]

36. Samandari M, Julia MG, Rice A, Chronopoulos A, del Río Hernández AE (2018) Liquid biopsies for management of pancreatic cancer. Transl Res 201: 98-127. [Crossref]

37. Riva F, Dronov OI, Khomenko DI, Huguet F, Louvet C, et al. (2016) Clinical applications of circulating tumor DNA and circulating tumor cells in pancreatic cancer. Mol Oncol 10: 481-493.

38. Bidard FC, Huguet F, Louvet C, Mineur L, Bouche O, et al. (2013) Circulating tumor cells in locally advanced pancreatic adenocarcinoma: the ancillary CirCe 07 study to the LAP 07 trial. Ann Oncol 24: 2057-2061.

39. Effenberger KE, Schroeder C, Hanssen A, Wolter S, Eulenburg C, et al. (2018) Improved risk stratification by circulating tumor cell counts in pancreatic cancer. Clin Cancer Res 24: 2844-2850. [Crossref]

40. Maire F, Micard S, Hammel P, Voitot H, Lévy P, et al. (2002) Differential diagnosis between chronic pancreatitis and pancreatic cancer: value of the detection of KRAS2 mutations in circulating DNA. Br J Cancer 87: 551-554

41. Pietrasz D, Pécuchet N, Garlan F, Didelot A, Dubreuil O, et al. (2017) Plasma circulating tumor DNA in pancreatic cancer patients is a prognostic marker. Clin Cancer Res 23: 116-123.

42. Chen H, Tu H, Meng ZQ, Chen Z, Wang P, et al. (2010) K-ras mutational status predicts poor prognosis in unresectable pancreatic cancer. Eur J Surg Oncol EJSO 36: 657-662.

43. Henriksen SD, Madsen PH, Krarup H, Thorlacius-Ussing O (2015) DNA hypermethylation as a blood-based marker for pancreatic cancer: A literature review. Pancreas 44: 1036-1045.

44. Kishikawa T, Otsuka M, Ohno M, Yoshikawa T, Takata A, et al. (2015) Circulating RNAs as new biomarkers for detecting pancreatic cancer. World J Gastroenterol 21: 8527-8540. [Crossref]

45. Wei L, Yao K, Gan S, Suo Z (2018) Clinical utilization of serum- or plasma-based miRNAs as early detection biomarkers for pancreatic cancer: A meta-analysis up to now. Medicine (Baltimore) 97: e12132. [Crossref]
46. Imamura T, Komatsu S, Ichikawa D, Miyamae M, Okajima W, et al. (2017) Depleted tumor suppressor miR-107 in plasma relates to tumor progression and is a novel therapeutic target in pancreatic cancer. Sci Rep 7: 5708.

47. Melo SA, Luecke LB, Kahlert C, Fernandez AF, Gammon ST, et al. (2015) Glypican-1 identifies cancer exosomes and detects early pancreatic cancer. Nature 523: 177-182.

48. Pagès F, Mlecnik B, Marliot F, Bindea G, Ou F-S, et al. (2018) International validation of the consensus Immunoscore for the classification of colon cancer: A prognostic and accuracy study. The Lancet 391: 2128-2139.

49. Tahkola K, Mecklin J-P, Wirta E-V, Ahtiainen M, Helminen O, et al. (2018) High immune cell score predicts improved survival in pancreatic cancer. Virchows Arch 472 653-665.

50. Farges O, Bendersky N, Truant S, Delpero JR, Pruvot FR, et al. (2017) The theory and practice of pancreatic surgery in france. Ann Surg 266: 797-804. [Crossref]

51. Heinrich S, Pestalozzi B, Lesurtel M, Berrevoet F, Laurent S, et al. (2011) Adjuvant gemcitabine versus NEOadjuvant gemcitabine/oxaliplatin plus adjuvant gemcitabine in resectable pancreatic cancer: A randomized multicenter phase III study (NEOPAC study). BMC Cancer 11: 346.

52. Hishinuma S, Ogata Y, Tomikawa M, Ozawa I, Hirabayashi K, et al. (2006) Patterns of recurrence after curative resection of pancreatic cancer, based on autopsy findings. $J$ Gastrointest Surg Off J Soc Surg Aliment Tract 10: 511-518.

53. Valle JW, Palmer D, Jackson R, Cox T, Neoptolemos JP, et al. (2014) Optimal duration and timing of adjuvant chemotherapy after definitive surgery for ductal adenocarcinoma of the pancreas: ongoing lessons from the ESPAC-3 study. J Clin Oncol Off J Am Soc Clin Oncol 32: 504-512.

54. Neoptolemos JP, Stocken DD, Bassi C, Ghaneh P, Cunningham D, et al. (2010) Adjuvant chemotherapy with fluorouracil plus folinic acid vs gemcitabine following pancreatic cancer resection: a randomized controlled trial. JAMA 304: 1073-1081.

55. Neoptolemos JP, Palmer DH, Ghaneh P, Psarelli EE, Valle JW, et al. (2017) Comparison of adjuvant gemcitabine and capecitabine with gemcitabine monotherapy in patients with resected pancreatic cancer (ESPAC-4): a multicentre, open-label, randomised, phase 3 trial. The Lancet 389: 1011-1024.

56. Conroy T, Hammel P, Hebbar M, Ben Abdelghani M, Wei AC, et al. (2018) FOLFIRINOX or gemcitabine as adjuvant therapy for pancreatic cancer. $N$ Engl $J$ Med 379: 2395-2406. [Crossref]

57. Uesaka K, Boku N, Fukutomi A, Okamura Y, Konishi M, et al. (2016) Adjuvan chemotherapy of S-1 versus gemcitabine for resected pancreatic cancer: a phase, openlabel, randomised, non-inferiority trial (JASPAC 01). Lancet Lond Engl 388: 248-257.

58. Sinn M, Bahra M, Liersch T, Gellert K, Messmann H, et al. (2017) CONKO-005: Adjuvant chemotherapy with gemcitabine plus erlotinib versus gemcitabine alone in patients after R0 resection of pancreatic cancer: A multicenter randomized phase III trial. J Clin Oncol Off J Am Soc Clin Oncol 35: 3330-3337.

59. Sinn M, Liersch T, Riess H, Gellert K, Stübs P, et al. (2014) LBA18-. CONKO-006: A randomized double-blinded phase IIb-study of adjuvant therapy with gemcitabine + sorafenib/placebo for patients with R1-resection of pancreatic cancer. Ann Oncol 25: $1-41$

60. Lutz MP, Zalcberg JR, Ducreux M, Aust D, Bruno MJ, et al. 3rd St. Gallen EORTC gastrointestinal cancer conference: Consensus recommendations on controversial issues in the primary treatment of pancreatic cancer. Eur J Cancer 79: 41-49.

61. Neoptolemos JP, Stocken DD, Friess H, Bassi C, Dunn JA, et al. (2004) A randomized trial of chemoradiotherapy and chemotherapy after resection of pancreatic cancer. $N$ Engl J Med 350: 1200-1210.

62. Van Laethem J-L, Hammel P, Mornex F, Azria D, Van Tienhoven G, et al. (2010) Adjuvant gemcitabine alone versus gemcitabine-based chemoradiotherapy after curative resection for pancreatic cancer: a randomized EORTC-40013-22012/FFCD9203/GERCOR phase II study. J Clin Oncol Off J Am Soc Clin Oncol 28: 4450-4456.

63. Pietrasz D, Marthey L, Wagner M, Blanc J-F, Laurent C, et al. (2015) Pathologic major response after FOLFIRINOX is prognostic for patients secondary resected for borderline or locally advanced pancreatic adenocarcinoma: An AGEO-FRENCH, prospective, multicentric cohort. Ann Surg Oncol 22 Suppl 3: S1196-1205.

64. Katz MHG, Shi Q, Ahmad SA, Herman JM, Marsh R de W, et al. (2016) Preoperative modified FOLFIRINOX treatment followed by capecitabine-based chemoradiation for borderline resectable pancreatic cancer: Alliance for clinical trials in oncology trial A021101. JAMA Surg 151: e161137.

65. Wagner M, Antunes C, Pietrasz D, Cassinotto C, Zappa M, et al. (2017) CT evaluation after neoadjuvant FOLFIRINOX chemotherapy for borderline and locally advanced pancreatic adenocarcinoma. Eur Radiol 27: 3104-3016. 
66. Burris HA, Moore MJ, Andersen J, Green MR, Rothenberg ML, et al. (1997) Improvements in survival and clinical benefit with gemcitabine as first-line therapy for patients with advanced pancreas cancer: a randomized trial. J Clin Oncol Off J Am Soc Clin Oncol 15: 2403-2413.

67. Hammel P, Huguet F, van Laethem J-L, Goldstein D, Glimelius B, et al. (2016) Effect of chemoradiotherapy vs chemotherapy on survival in patients with locally advanced pancreatic cancer controlled after 4 months of gemcitabine with or without erlotinib: The LAP07 randomized clinical trial. JAMA 315: 1844-1853.

68. Marthey L, Sa-Cunha A, Blanc JF, Gauthier M, Cueff A, et al. (2015) FOLFIRINOX for locally advanced pancreatic adenocarcinoma: results of an AGEO multicenter prospective observational cohort. Ann Surg Oncol 22: 295-301.

69. Suker M, Beumer BR, Sadot E, Marthey L, Faris JE, et al. (2016) FOLFIRINOX for locally advanced pancreatic cancer: a systematic review and patient-level metaanalysis. Lancet Oncol 17: 801-810.

70. Hammel P, Lacy J, Portales F, Sobrero AF, Pazo Cid RA, et al. (2018) Phase II LAPACT trial of nab-paclitaxel (nab-P) plus gemcitabine $(\mathrm{G})$ for patients with locally advanced pancreatic cancer (LAPC). J Clin Oncol 36: 204

71. Huguet F, Rivin Del Campo E, Antoni D, Vendrely V, et al. Role of radiation therapy in the management of pancreatic cancer. Cancer Radiother J Soc Francaise Radiother Oncol 22: 552-557.

72. Loehrer PJ, Feng Y, Cardenes H, Wagner L, Brell JM, et al. Gemcitabine alone versus gemcitabine plus radiotherapy in patients with locally advanced pancreatic cancer: An Eastern Cooperative Oncology Group trial. J Clin Oncol Off J Am Soc Clin Oncol 29: 4105-4112.

73. Huguet F, André T, Hammel P, Artru P, Balosso J, et al. (2007) Impact of chemoradiotherapy after disease control with chemotherapy in locally advanced pancreatic adenocarcinoma in GERCOR phase II and III studies. J Clin Oncol Off J Am Soc Clin Oncol 25: 326-331.

74. Mukherjee S, Hurt CN, Bridgewater J, Falk S, Cummins S, et al. (2013) Gemcitabinebased or capecitabine-based chemoradiotherapy for locally advanced pancreatic cancer (SCALOP): a multicentre, randomised, phase 2 trial. Lancet Oncol 14: 317-326. [Crossref]

75. Ciliberto D, Botta C, Correale P, Rossi M, Caraglia M, et al. (2013) Role of gemcitabinebased combination therapy in the management of advanced pancreatic cancer: a metaanalysis of randomised trials. Eur J Cancer Oxf Engl 49: 593-603.

76. Xie D, Yang Q, Chen D, Jiang Z, Bi Z, et al. (2010) Gemcitabine-based cytotoxic doublets chemotherapy for advanced pancreatic cancer: updated subgroup metaanalyses of overall survival. Jpn J Clin Oncol 40: 432-441.

77. Rougier P, Riess H, Manges R, Karasek P, Humblet Y, et al. (2013) Randomised, placebo-controlled, double-blind, parallel-group phase III study evaluating aflibercept in patients receiving first-line treatment with gemcitabine for metastatic pancreatic cancer. Eur J Cancer Oxf Engl 49: 2633-2642.

78. Philip PA, Benedetti J, Corless CL, Wong R, O’Reilly EM, Flynn PJ, et al. (2010) Phase III study comparing gemcitabine plus cetuximab versus gemcitabine in patients with advanced pancreatic adenocarcinoma: Southwest oncology group-directed intergroup trial S0205. J Clin Oncol Off J Am Soc Clin Oncol 28: 3605-3610.

79. Moore MJ, Goldstein D, Hamm J, Figer A, Hecht JR, et al. (2007) Erlotinib plus gemcitabine compared with gemcitabine alone in patients with advanced pancreatic cancer: A phase III trial of the National Cancer Institute of Canada Clinical Trials Group. J Clin Oncol Off J Am Soc Clin Oncol 25: 1960-1966.

80. Conroy T, Desseigne F, Ychou M, Bouché O, Guimbaud R, et al. (2011) FOLFIRINOX versus gemcitabine for metastatic pancreatic cancer. $N$ Engl J Med 364: 1817-1825.

81. Mahaseth H, Brutcher E, Kauh J, Hawk N, Kim S, et al. (2013) Modified FOLFIRINOX regimen with improved safety and maintained efficacy in pancreatic adenocarcinoma. Pancreas 42: 1311-1315.

82. Von Hoff DD, Ervin T, Arena FP, Chiorean EG, Infante J, et al. (2013) Increased survival in pancreatic cancer with nab-paclitaxel plus gemcitabine. N Engl J Med 369: 1691-1703. [Crossref]

83. Chan K, Shah K, Lien K, Coyle D, Lam H, et al. A Bayesian meta-analysis of multiple treatment comparisons of systemic regimens for advanced pancreatic cancer. PloS One 9: e108749.

84. Collins DC, Morris PG (2015) Systemic therapy for advanced pancreatic cancer: individualising cytotoxic therapy. Expert Opin Pharmacother 16: 851-861. [Crossref]

85. Wang-Gillam A, Li C-P, Bodoky G, Dean A, Shan Y-S, et al. (2016) Nanoliposomal irinotecan with fluorouracil and folinic acid in metastatic pancreatic cancer after previous gemcitabine-based therapy (NAPOLI-1): a global, randomised, open-label, phase 3 trial. Lancet Lond Engl 387: 545-557.
86. Hammel P, Bachet J-B, Portales F, Mineur L, Metges J-P, et al. (2017) 621PDA Phase $2 \mathrm{~b}$ of eryaspase in combination with gemcitabine or FOLFOX as second-line therapy in patients with metastatic pancreatic adenocarcinoma (NCT02195180). Ann Oncol 28: suppl_5

87. Oettle H, Riess H, Stieler JM, Heil G, Schwaner I, et al. (2014) Second line oxaliplatin, folinic acid, and fluorouracil versus folinic acid and fluorouracil alone for gemcitabinerefractory pancreatic cancer: outcomes from the CONKO-003 trial. J Clin Oncol Off $J$ Am Soc Clin Oncol 32: 2423-2429.

88. Gill S, Ko Y-J, Cripps C, Beaudoin A, Dhesy-Thind S, et al. (2016) PANCREOX: A randomized phase III study of fluorouracil/leucovorin with or without oxaliplatin for second-line advanced pancreatic cancer in patients who have received gemcitabinebased chemotherapy. J Clin Oncol Off J Am Soc Clin Oncol 34: 3914-3920.

89. Cintas C, Douché T, Therville N, Arcucci S, Ramos-Delgado F, et al. (2018) Signaltargeted therapies and resistance mechanisms in pancreatic cancer: Future developments reside in proteomics. Cancers 10: 174.

90. Collisson EA, Sadanandam A, Olson P, Gibb WJ, Truitt M, et al. (2011) Subtypes of pancreatic ductal adenocarcinoma and their differing responses to therapy. Nat Med 17: 500-503.

91. Moffitt RA, Marayati R, Flate EL, Volmar KE, Loeza SGH, et al. (2015) Virtua microdissection identifies distinct tumor- and stroma-specific subtypes of pancreatic ductal adenocarcinoma. Nat Genet 47: 1168-1178.

92. Australian Pancreatic Cancer Genome Initiative, Bailey P, Chang DK, Nones K, Johns $\mathrm{AL}$, et al. (2016) Genomic analyses identify molecular subtypes of pancreatic cancer. Nature 531: 47-52.

93. Australian Pancreatic Cancer Genome Initiative, Waddell N, Pajic M, Patch A-M Chang DK, et al. (2015) Whole genomes redefine the mutational landscape of pancreatic cancer. Nature 518: 495-501

94. Apte MV, Wilson JS, Lugea A, Pandol SJ (2013) A starring role for stellate cells in the pancreatic cancer microenvironment. Gastroenterology 144: 1210-1219.

95. Erkan M, Michalski CW, Rieder S, Reiser-Erkan C, Abiatari I, et al. (2008) The activated stroma index is a novel and independent prognostic marker in pancreatic ductal adenocarcinoma. Clin Gastroenterol Hepatol 6: 1155-1161.

96. Provenzano PP, Cuevas C, Chang AE, Goel VK, Von Hoff DD, et al. (2012) Enzymatic targeting of the stroma ablates physical barriers to treatment of pancreatic ducta adenocarcinoma. Cancer Cell 21: 418-429.

97. Hingorani SR, Zheng L, Bullock AJ, Seery TE, Harris WP, et al. (2018) HALO 202: Randomized phase II study of PEGPH20 plus nab-paclitaxel/gemcitabine versus nab-paclitaxel/gemcitabine in patients with untreated, metastatic pancreatic ductal adenocarcinoma. J Clin Oncol Off J Am Soc Clin Oncol 36: 359-366.

98. Ramanathan RK (2018) A phase IB/II randomized study of mFOLFIRINOX (mFFOX) + pegylated recombinant human hyaluronidase (PEGPH20) versus $\mathrm{mFFOX}$ alone in patients with good performance status metastatic pancreatic adenocarcinoma (mPC): SWOG S131 (NCT \#01959139). J clin oncol 36: 208-208.

99. Golan T, Kanji ZS, Epelbaum R, Devaud N, Dagan E, et al. (2014) Overall survival and clinical characteristics of pancreatic cancer in BRCA mutation carriers. Br J Cancer 111: $1132-1138$

100. Luo G, Lu Y, Jin K, Cheng H, Guo M, et al. (2015) Pancreatic cancer: BRCA mutation and personalized treatment. Expert Rev Anticancer Ther 15: 1223-12231.

101. Shroff RT, Hendifar A, McWilliams RR, Geva R, Epelbaum R, et al. (2018) Rucaparib monotherapy in patients with pancreatic cancer and a known deleterious BRCA mutation. JCO Precis Oncol 2: 1-15.

102. Lowery MA, Kelsen DP, Capanu M, Smith SC, Lee JW, Stadler ZK, et al. (2018) Phase II trial of veliparib in patients with previously treated BRCA-mutated pancreas ductal adenocarcinoma. Eur J Cancer 89: 19-26.

103. Bendell J, O’Reilly EM, Middleton MR, Chau I, Hochster H, et al. (2015) Phase I study of olaparib plus gemcitabine in patients with advanced solid tumours and comparison with gemcitabine alone in patients with locally advanced/metastatic pancreatic cancer. Ann Oncol 26: 804-811.

104. O'Reilly EM, Lee JW, Lowery MA, Capanu M, Stadler ZK, et al. (2018) Phase 1 tria evaluating cisplatin, gemcitabine, and veliparib in 2 patient cohorts: Germline BRCA mutation carriers and wild-type BRCA pancreatic ductal adenocarcinoma: Pancreatic Cancer, PARP Inhibitor, Cisplatin. Cancer 124: 1374-1382.

105. Connor AA, Denroche RE, Jang GH, Timms L, Kalimuthu SN, et al. (2017) Association of distinct mutational signatures with correlates of increased immune activity in pancreatic ductal adenocarcinoma. JAMA Oncol 3: 774. 
106. Lord CJ, Ashworth A (2016) BRCAness revisited. Nat Rev Cancer 16: 110-120. [Crossref]

107. Swarm RA, Gafford E, Rabow MW (2018) NCCN guidelines index table of contents discussion. 96

108. Zhong W, Yu Z, Zeng JX, Lin Y, Yu T, et al. (2014) Celiac plexus block for treatment of pain associated with pancreatic cancer: a meta-analysis. Pain Pract 14: 43-51. [Crossref]

109. Khorana AA, Kuderer NM, Culakova E, Lyman GH, Francis CW (2008) Development and validation of a predictive model for chemotherapy-associated thrombosis. Blood 111: 4902-4907.

110. Gärtner S, Krüger J, Aghdassi AA, Steveling A, Simon P, et al. (2016) Nutrition in pancreatic cancer: A review. Gastrointest Tumors 2: 195-202.

111. Trestini I, Carbognin L, Sperduti I, Bonaiuto C, Auriemma A, et al. (2018) Prognostic impact of early nutritional support in patients affected by locally advanced and metastatic pancreatic ductal adenocarcinoma undergoing chemotherapy. Eur J Clin Nutr 72: 772-779.

112. Arends J, Bachmann P, Baracos V, Barthelemy N, Bertz H, et al. (2017) ESPEN guidelines on nutrition in cancer patients. Clin Nutr 36: 11-48. [Crossref]

113. Network NACRe - National network food cancer research - Report NACRe fasting restrictive diets. Cancer 2017.

114. Mishra SI, Scherer RW, Snyder C, Geigle PM, Berlanstein DR, et al. Exercise interventions on health-related quality of life for people with cancer during active treatment. Cochrane Database Syst Rev 8: CD008465.

115. Velthuis MJ, Agasi-Idenburg SC, Aufdemkampe G, Wittink HM (2010) The effect of physical exercise on cancer-related fatigue during cancer treatment: a meta-analysis of randomised controlled trials. Clin Oncol R Coll Radiol G B 22: 208-221.

116. Speck RM, Courneya KS, Mâsse LC, Duval S, Schmitz KH (2010) An update of controlled physical activity trials in cancer survivors: a systematic review and metaanalysis. J Cancer Surviv Res Pract 4: 87-100.

117. Ballard-Barbash R, Friedenreich CM, Courneya KS, Siddiqi SM, McTiernan A, et al Physical activity, biomarkers, and disease outcomes in cancer survivors: a systematic review. J Natl Cancer Inst 104: 815-840.

118. Massoner P, Ladurner-Rennau M, Eder IE, Klocker H (2010) Insulin-like growth factors and insulin control a multifunctional signalling network of significant importance in cancer. Br J Cancer 103: 1479-1484.

119. Kruijsen-Jaarsma M, Révész D, Bierings MB, Buffart LM, Takken T (2013) Effects of exercise on immune function in patients with cancer: a systematic review. Exerc Immunol Rev 19: 120-143.

120. de Salles BF, Simão R, Fleck SJ, Dias I, Kraemer-Aguiar LG, et al. (2010) Effects of resistance training on cytokines. Int J Sports Med 31: 441-450. [Crossref]

121. Neuzillet C, Vergnault M, Bonnetain F, Hammel P (2015) Rationale and design of the adapted physical activity in advanced pancreatic cancer patients (APACaP) GERCOR (Groupe Coopérateur Multidisciplinaire en Oncologie) trial: study protocol for a randomized controlled trial. Trials 16: 454.

122. Van Cutsem E, Hidalgo M, Canon J-L, Macarulla T, Bazin I, et al. (2018) Phase I/ II trial of pimasertib plus gemcitabine in patients with metastatic pancreatic cancer: Pimasertib plus gemcitabine in pancreatic cancer. Int J Cancer 143: 2053-2064. [Crossref]
123. Tolcher AW, Bendell JC, Papadopoulos KP, Burris HA 3rd, Patnaik A, et al. (2015) A phase IB trial of the oral MEK inhibitor trametinib (GSK1120212) in combination with everolimus in patients with advanced solid tumors. Ann Oncol 26: 58-64. [Crossref]

124. Zorde Khvalevsky E, Gabai R, Rachmut IH, Horwitz E, Brunschwig Z, et al. (2013) Mutant KRAS is a druggable target for pancreatic cancer. Proc Natl Acad Sci USA 110: 20723-20728. [Crossref]

125. Noonan AM, Farren MR, Geyer SM, Huang Y, Tahiri S, et al. (2016) Randomized phase 2 trial of the oncolytic virus pelareorep (Reolysin) in upfront treatment of metastatic pancreatic adenocarcinoma. Mol Ther 24: 1150-1158.

126. Mahalingam D, Goel S, Aparo S, Patel Arora S, Noronha N, et al. (2018) A phase

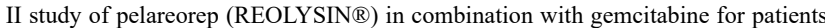
with advanced pancreatic adenocarcinoma. Cancers 10: 160.

127. Zhao X, Liu L, Lang J, Cheng K, Wang Y, et al. (2018) A CRISPR-Cas13a system for efficient and specific therapeutic targeting of mutant KRAS for pancreatic cancer treatment. Cancer Lett 431: 171-181.

128. Van Sciver R, Lee M, Lee C, Lafever A, Svyatova E, et al. (2018) A new strategy to control and eradicate "undruggable" oncogenic K-RAS-driven pancreatic cancer: molecular insights and core principles learned from developmental and evolutionary biology. Cancers 10: 142.

129. Bigelsen S (2018) Evidence-based complementary treatment of pancreatic cancer: review of adjunct therapies including paricalcitol, hydroxychloroquine, intravenous vitamin C, statins, metformin, curcumin, and aspirin. Cancer Manag Res 10: 2003 2018 .

130. Wolpin BM, Rubinson DA, Wang X, Chan JA, Cleary JM, et al. (2014) Phase Il and pharmacodynamic study of autophagy inhibition using hydroxychloroquine in patients with metastatic pancreatic adenocarcinoma. The Oncologist 19: 637-638.

131. Hingorani SR, Zheng L, Bullock AJ, Seery TE, Harris WP, et al. (2018) HALO 202: Randomized phase II Study of PEGPH20 plus nab-paclitaxel/gemcitabine versus nab-paclitaxel/gemcitabine in patients with untreated, metastatic pancreatic ductal adenocarcinoma. J Clin Oncol 36: 359-366.

132. Oettle H, Seufferlein T, Luger T, Schmid RM, Wichert G, et al. (2012) Final results of a phase I/II study in patients with pancreatic cancer, malignant melanoma, and colorectal carcinoma with trabedersen. ASCO: Journal of clinical oncology Abstract: 4034.

133. Melisi D, Garcia-Carbonero R, Macarulla T, Pezet D, Deplanque G, et al. (2018) Galunisertib plus gemcitabine vs. gemcitabine for first-line treatment of patients with unresectable pancreatic cancer. Br J Cancer 119: 1208-1214.

134. Le DT, Lutz E, Uram JN, Sugar EA, Onners B, et al. (2013) Evaluation of ipilimumab in combination with allogeneic pancreatic tumor cells transfected with a GM-CSF gene in previously treated pancreatic cancer: J Immunother 36: 382-389.

135. Nywening TM, Wang-Gillam A, Sanford DE, Belt BA, Panni RZ, et al. (2016) Targeting tumour-associated macrophages with CCR2 inhibition in combination with FOLFIRINOX in patients with borderline resectable and locally advanced pancreatic cancer: A single-centre, open-label, dose-finding, non-randomised, phase $1 \mathrm{~b}$ trial Lancet Oncol 17: 651-662.

Copyright: (C2019 Clementine R. This is an open-access article distributed under the terms of the Creative Commons Attribution License, which permits unrestricted use, distribution, and reproduction in any medium, provided the original author and source are credited. 